\title{
Management factors associated with bovine respiratory disease in preweaned calves on California dairies: The BRD 100 study
}

\author{
G. U. Maier, ${ }^{1}$ W. J. Love, ${ }^{1 *}$ B. M. Karle, ${ }^{2}$ S. A. Dubrovsky, ${ }^{1}$ D. R. Williams, ${ }^{1}$ J. D. Champagne, ${ }^{1}$ R. J. Anderson, ${ }^{3}$ \\ J. D. Rowe, ${ }^{4}$ T. W. Lehenbauer, ${ }^{1,4}$ A. L. Van Eenennaam, ${ }^{5}$ and S. S. Aly ${ }^{1,4} \dagger$ \\ ${ }^{1}$ Veterinary Medicine Teaching and Research Center, School of Veterinary Medicine, University of California Davis, Tulare 93274 \\ ${ }^{2}$ Cooperative Extension, Division of Agriculture and Natural Resources, University of California, Orland 95963 \\ ${ }^{3}$ California Department of Food and Agriculture, Animal Health Branch, Modesto District, Modesto 95358 \\ ${ }^{4}$ Department of Population Health \& Reproduction, School of Veterinary Medicine, and \\ ${ }^{5}$ Department of Animal Science, University of California Davis, Davis 95616
}

\section{ABSTRACT}

The objective of this cross-sectional study was to determine how management practices on California dairies may be associated with bovine respiratory disease (BRD) in preweaned calves. A convenience sample of 100 dairies throughout California, providing a study population of 4,636 calves, were visited between May 2014 and April 2016. During each farm visit, in-person interviews with the herd manager or calf caretaker were conducted to collect information about herd demographics, maternity pen, colostrum and calf management, herd vaccinations, and dust abatement. A random sample of preweaned calves was identified and evaluated for the presence of BRD using a standardized tool. A survey-adjusted generalized linear mixed model with a logit link function was fitted with calf as the unit of analysis and dairy as the random effect. Mean study herd size $( \pm$ SE) was 1,718 $( \pm 189.9)$ cows. Survey-adjusted estimates of breed types in the sample were $81.6 \%( \pm 0.6)$ Holstein, $13.1 \%( \pm 0.4)$ Jersey, and $5.3 \%( \pm 0.5)$ crossbred or other purebred breeds, and calf sex proportions were $73.8 \%( \pm 1.0)$ female and $26.2 \%( \pm 1.0)$ male. Overall survey-adjusted BRD prevalence in the study herds was $6.91 \%( \pm 0.69)$. Housing factors positively associated with BRD were metal hutches compared with wood hutches [odds ratio $(\mathrm{OR})=11.19 ; 95 \%$ confidence interval $(\mathrm{CI})=$ 2.80-44.78], calf-to-calf contact in calves $>75 \mathrm{~d}$ of age $(\mathrm{OR}=9.95,95 \% \mathrm{CI}=1.50-65.86)$, feeding Holstein calves $<2.84 \mathrm{~L}$ of milk or replacer per day $(\mathrm{OR}=$

Received March 20, 2017.

Accepted July 25, 2018.

${ }^{*}$ Current address: Department of Population Health and Pathobiology, College of Veterinary Medicine, North Carolina State University, Raleigh, NC 27607.

$\dagger$ Corresponding author: saly@ucdavis.edu
7.16, 95\% CI $=1.23-41.68$ ), and lagoon water used for flushing manure under hutches compared with no flush $(\mathrm{OR}=12.06,95 \% \mathrm{CI}=1.93-75.47)$. Providing extra shade over hutches $(\mathrm{OR}=0.08 ; 95 \% \mathrm{CI}=0.02-0.37)$, feeding calves at least $90 \%$ saleable milk $(\mathrm{OR}=0.27$, $95 \% \mathrm{CI}=0.13-0.54)$ or pasteurized milk $(\mathrm{OR}=0.10$; $95 \% \mathrm{CI}=0.03-0.36)$, and feeding $>5.68 \mathrm{~L}$ of milk or replacer per day to Jersey calves $(\mathrm{OR}=0.04 ; 95 \% \mathrm{CI}=$ 0.01-0.28) were negatively associated with BRD. Our study identified management practices on California dairies with variability and that may contribute to differences in BRD prevalence, which will be incorporated into a risk-assessment tool to control and prevent BRD in preweaned dairy calves.

Key words: dairy calf, bovine respiratory disease, risk factors

\section{INTRODUCTION}

Bovine respiratory disease (BRD) complex is one of the most common causes of death in dairy calves and poses a significant welfare and economic burden on the industry (Panciera and Confer, 2010). Reported morbidities for calves in the 1991 NAHMS study evaluating the health of preweaning heifers on dairies was only $8.9 \%$ in calves up to 8 weeks of age (USDA, 1994). In 2010, respiratory disease in dairy heifers was reported as the cause in $22.5 \%$ of deaths before and $46.5 \%$ of deaths after weaning (USDA, 2010). In addition, 18.1\% of preweaning heifers on dairy heifer-raising operations were reportedly affected by pneumonia, making it the second most common calf illness after diarrhea (USDA, 2012). Hence, over the last few decades, no improvement has been reported in morbidity from BRD in dairy calves.

Given the lack of improvement in BRD incidence in US dairy cattle, despite the availability of numerous vaccines and antimicrobial drugs labeled for BRD, novel approaches that target prevention in addition to control 
should be evaluated. The complexity of etiologic agents and predisposing factors for BRD combined with the difficulty of accurate diagnosis pose challenges in the prevention and control of this disease on the farm that may be addressed using a risk-assessment approach in combination with a disease-scoring system. A multitude of tests can be used to identify pneumonia calves in a herd; however, scoring systems require minimal training, are low cost, and can be reasonably accurate, making them a viable tool to estimate the disease burden in the herd (Love et al., 2014, 2016b). Repeated use of a risk-assessment tool to target preventive management practices combined with a scoring system to benchmark the burden of BRD in a calf herd over time may offer a low-cost, rapid, and comprehensive control program for BRD. In contrast to a chronic disease, such as Johne's disease, where changes implemented to control the disease may not result in a reduction in incidence for many years, BRD primarily presents as an acute disease. With the daily influx of newborn calves, changes in incidence may be observed within months of implementation of the prevention or control program.

Dairies in California differ in many ways from dairies in other parts of the United States. For example, the average dairy herd size for California in 2016 was 1,249 milking cows, with herds up to 10,000 milking cows, whereas the latest report on dairy cattle management practices published by USDA categorizes herd sizes with more than 500 cows as large (California Department of Food and Agriculture, 2016; USDA, 2016a). Other differences include California's climate, which allows for year-round outdoor housing of calves and cattle, which is impractical in many parts of the country (Lago et al., 2006). Climate and dairy management practices in California are not homogeneous across the state, however. As an example, in 2011, California held $22.6 \%$ of the nation's organic dairy cows, most of which were found in the northern part of the state (USDA, 2011). It is clear, that the development of a risk-assessment tool for California dairies cannot be based on national averages but should be based on data collected from within this unique industry. The objective of our study was to identify factors associated with BRD in preweaned calves on California dairies by correlating management practices on California dairy farms to prevalence of $\mathrm{BRD}$ in calves exposed to these practices. Our hypothesis was that BRD is associated with management practices related to risk factors for $\mathrm{BRD}$, such as the amount of colostrum and milk fed, housing type, and vaccinations. The research described here is a further step in the development of a risk-assessment tool for BRD in preweaned calves on California dairies following the survey of management practices related to BRD in preweaned calves on California dairies (Love et al., 2016a).

\section{MATERIALS AND METHODS}

\section{Study Design and Recruitment}

A cross-sectional study was designed to collect data on management practices and estimate BRD prevalence in preweaned dairy calves on a convenience sample of California dairies. In 2013, managers of 1,523 California dairy herds were surveyed using 2 mail questionnaires followed by a reminder card after each mailing. The survey aimed to identify the variety of management practices known to be associated with the incidence of $\mathrm{BRD}$ in preweaned calves with the purpose of characterizing these practices, comparing them across geographic regions of the state, and determining the principal components that explain the variability in management between herds (Love et al., 2016a). Respondents to the survey were given the option of providing contact information if they were interested in participating in a follow-up study. In addition to respondents who showed willingness for a follow-up herd visit, we sought local dairies, veterinarians, consultants, farm advisors, and dairy owners through personal contacts to enroll farms. Emphasis was placed on inclusion of a wide range of herd sizes, geographical locations, and management styles into the sample. The study protocol was approved by the University of California at Davis Animal Care and Use Committee (Approval \# 19241).

\section{Sample Size}

A sample of 100 dairies was targeted, which is the number of groups required to obtain unbiased estimates for fixed effects if group sizes are 50 or higher (Moineddin et al., 2007). A sample size calculation for the number of dairies required to estimate the state prevalence of BRD in California yielded $\mathrm{n}=94$ based on a total of 1,470 dairies $(n=1,470)$ in the state and assuming a conservative prevalence estimate of 0.5 , to maximize $\mathrm{n}$. The sample size to estimate the state prevalence was calculated using the formula

$$
n=\frac{N \times p \times(1-p)}{(N-1) \times \frac{B^{2}}{4}+p \times(1-p)},
$$

where $n=$ number of dairies in the state, $p=0.5$, and $B=10 \%$ for the bound on the error of estimation of $p$ $=0.1=2 \sqrt{\operatorname{Var}(\hat{p})}$ (Scheaffer et al., 2012). Within dair- 
ies, a simple random sample of calves was drawn to estimate the prevalence of BRD on each of the participating dairies based on equation 1 , but where $n=$ number of calves on the farm, $p=0.25$ for the estimate of herd prevalence (Love et al., 2016b), and $B=10 \%$ for the bound on the error of estimation of $P=0.1=$ $2 \sqrt{\operatorname{Var}(\hat{p})}$ (Scheaffer et al., 2012).

\section{Questionnaire Design}

The 11 principal components identified in the 2013 survey formed the basis for the on-farm questionnaire (Love et al., 2016a). Briefly, the questionnaire collected information about demographics (location, herd size, and organic or conventional production), maternity pen management (density and individual or group pens), colostrum management (source, heat treatment, storage, quality, volume fed, and testing of calves for failure of transfer of passive immunity), calf management (housing, time of weaning, treatment of sick calves, criteria for treatment, and type and volume of milk fed), vaccinations (type, timing, and frequency of administration to adult cattle and calves), and dust abatement (whether perceived as a problem and type of abatement).

\section{Study Outcome}

Study outcome was the presence of BRD at the time of the visit in a simple random sample of calves at the dairy that were either housed individually or housed in groups provided they were fed milk as part or all of their diet. Calves were scored using the standardized and validated California scoring system for BRD in preweaned calves based on a point system (Love et al., 2014). In the California scoring system, points are assigned for the presence of each of these clinical signs: 2 points for cough, ocular discharge, dyspnea, or a rectal temperature of $\geq 39.2^{\circ} \mathrm{C}\left(102.5^{\circ} \mathrm{F}\right) ; 4$ points for nasal discharge; and 5 points for a head tilt or ear droop. A calf that scores 5 points or more is scored as positive for BRD.

\section{Farm Visits}

Dairies were visited between May 2014 and April 2016 and in-person interviews with owners or herd managers were conducted. The 10 individuals conducting the interviews consisted of veterinarians, graduate students, research assistants, animal scientists, extension and outreach specialists, and farm advisors who were all familiar with the California dairy industry. All interviewers were trained on the use of the California
BRD scoring system and were accompanied by a more experienced team member during their first farm visit. Interviewees were instructed to answer questions based on management practices in place only as far back as when the oldest calf eligible to be enrolled was born. The number of calves on the premises was determined as part of the questionnaire. Once the questionnaire was completed, study personnel proceeded to score a random number of calves based on the total number of calves on the farm to estimate the calf herd's BRD prevalence. The random sample was drawn from all individually housed calves and calves in groups on a milk diet and included calves that were recently weaned if still housed in a hutch. Sample sizes of calves to be scored for $\mathrm{N}=100(\mathrm{n}=44), 250(\mathrm{n}=58), 500(\mathrm{n}=$ 66), $750(\mathrm{n}=69), 1,000(\mathrm{n}=70)$, and 1,500 $(\mathrm{n}=72)$ calves on the farm were calculated per equation 1 and sheets with random numbers between 1 and $N$ prepared in a spreadsheet (Excel 2007-2016, Microsoft Corp., Redmond, WA). The sheet with the next larger $N$ was used for selecting the sample of calves. Scoring started typically with the youngest calf followed by counting of hutches according to the random number sheet until the next calf on the list was reached and scored and so on until the oldest eligible calf was reached. Apart from the clinical signs that are part of the BRD score, the calf's ear tag number, sex, and date of birth were recorded. Breed was recorded as Holstein, Jersey, or other, the latter including other purebred breeds as well as crossbred animals. Hutch type for each calf was described in terms of floor and wall materials, whether a roof was partial, full, or absent, whether extra shade was provided, and the dimensions of the hutch or pen. In addition, the elevation of the hutch floor from the ground, the presence and type of a flush system for manure, and the number of calves in the enclosure were recorded as well as whether calf-to-calf contact with other calves was possible. Further, the distance from the hutch to the nearest dust area was measured. Maternity pens were visited, dimensions of pens were measured, and hygiene scores for 15 cows were assigned according to a 4-point system. A score of 1 indicated no manure soiling above the pastern; score 2 indicated manure soiling on the lower leg; score 3 indicated manure soiling on the upper leg, udder, and abdomen; and score 4 indicated manure soiling on udder or abdomen and toward spine (Farmers Assuring Responsible Management, 2016). If fewer than 15 cows were present in the maternity pen, all cows present were scored. The dimensions of hutches (width and depth) as well as maternity pens and group pens (width and depth) were measured in feet and inches and transformed to metric measurements for analysis. 


\section{Missing Data}

Of 5,034 calves that were originally enrolled, 398 calves on 4 dairies were removed from analysis due to missing information on their date of birth. Several dairies kept records with approximate ages of calves (e.g., birth month), but these 312 calves were also excluded from the final model once age was confirmed as an important confounder. Calves that had missing data for any of the predictors in the final multivariable model were excluded from analysis as well, resulting in 4,253 calves in the final model (Figure 1). No imputation of missing data was performed. Survey-weighted proportions of calves missing from the analysis were compared with calves in the final model in terms of prevalence with Pearson's chi-squared test.

\section{Statistical Analysis}

All statistical analyses were performed using a commercial software package (Stata 14.2, Stata Corp., College Station, TX). Calf-level explanatory variables included age, breed, and sex; housing-related variables, such as the type of hutch the calf is housed in, including the wall and floor materials; whether extra shade was available; whether the hutch was elevated or not; whether or not calf-to-calf contact was possible; whether the calf was individually housed or in groups; if and

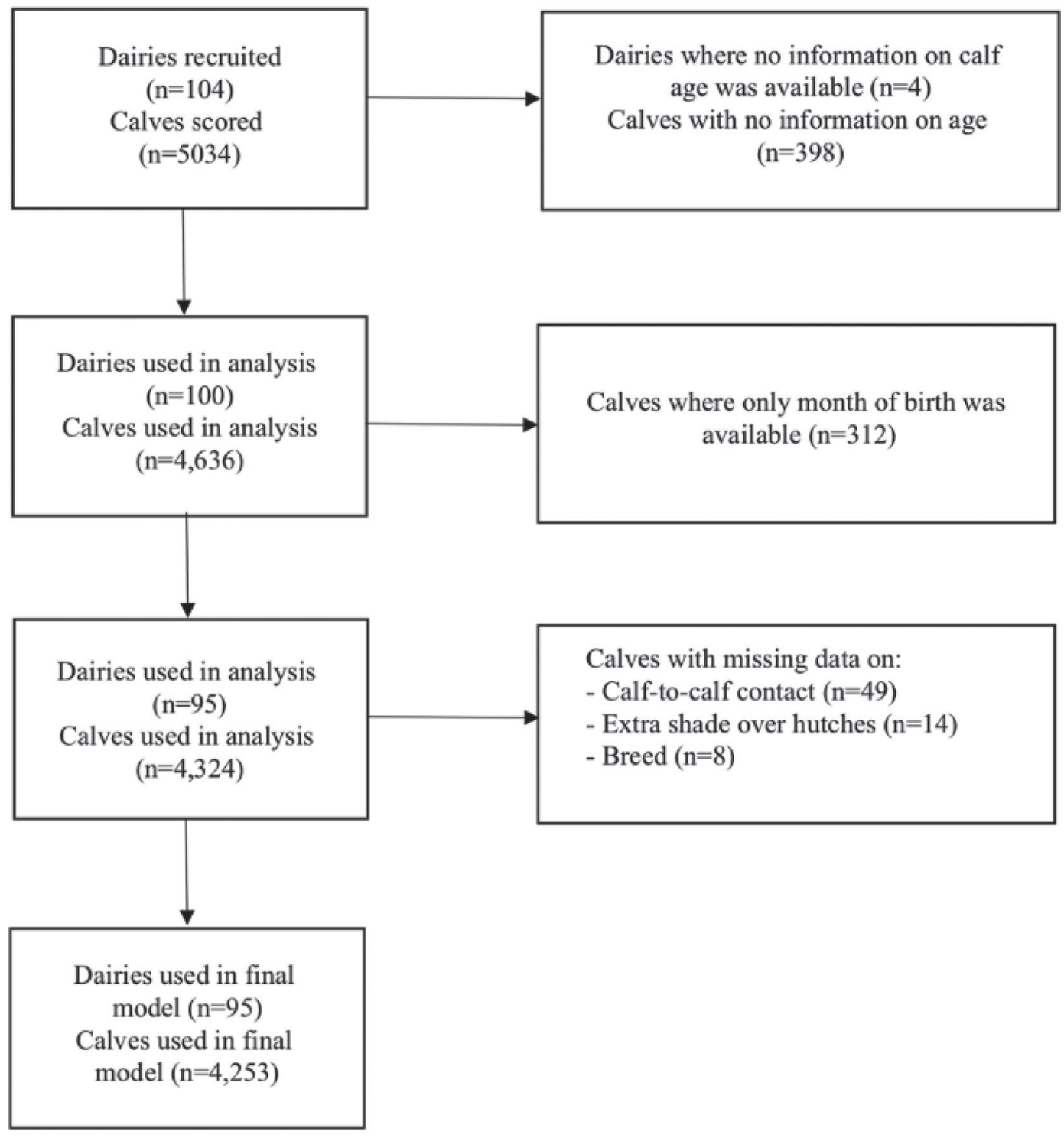

Figure 1. Flowchart of number of dairies and calves eliminated from final analysis of 5,034 calves on 104 dairies surveyed between May 2014 and April 2016 relating management practices to bovine respiratory disease (BRD) prevalence. 
what type of flush system for manure was in place; and what type of surfaces were close to the calves. In addition, milk-feeding related variables were assigned at the calf level by recording each calf's age and relating it to the source and amount of milk being fed, and whether or not the milk was pasteurized or anything was added to the milk. Vaccine-related variables were at the calf level by determining whether or not a calf had received a certain vaccine based on the age of the calf and the vaccination protocol discussed while filling in the questionnaire. All other variables, such as all variables relating to maternity pen management, colostrum management, vaccinations of cows and heifers, or herd demographics, were recorded at the herd level. All analyses were performed at the calf level with the unit of analysis being the calf and values of $P<0.05$ considered significant.

Relational Database Design. Individual calves scored during visits were matched to questionnaire answers by dairy identification in a database (Access 2007-2016, Microsoft Corp.). Calf records were linked to survey responses with a query in Access, matching the age, sex, and breed demographics of the calf to the respective management based on the survey. Most differences in management were related to the amount, source, or number of milk feedings by age, but also included different timing of movement to group housing by breed or management differences concerning diet or colostrum by breed or sex. All records were checked for completeness, plausibility, and accuracy.

Descriptive Statistics. Characteristics of dairies and calves in the sample were described using proportions for categorical and means for continuous variables as well as standard errors and 95\% confidence intervals of these estimates. Estimates at the calf level, including prevalence estimates, were survey adjusted, where each observation was weighted by the inverse of the sampling fraction $\left(1 / f_{j}\right)$, with $f_{j}$ being the number of calves scored divided by the number of calves on the jth premises. Comparisons between levels of categorical variables were performed with chi-squared tests and BonferroniDunn adjustments for multiple comparisons. Strata with single sampling units were omitted from proportion estimates because they prevented calculation of a standard error.

Multivariable Logistic Regression Model. The dependent variable for all analyses was the presence or absence of BRD in study calves, as assessed via the California BRD scoring system. Continuous variables were assessed for linearity using the Box Tidwell test (Box and Tidwell, 1962). Variables that did not meet this criterion were categorized using biologically sensible cut points. Two-by-two tables of categorical variables with case status were inspected for cell frequencies and categories were collapsed as necessary to achieve cell sizes of 5 or greater.

Survey-adjusted univariate generalized linear mixed models with a logit link function with a random effect for dairy were fitted to each variable with the melogit command in Stata. Variables were then added one at a time to a survey-adjusted multivariable generalized linear mixed model with a logit link function with dairy as a random effect. Variables were assessed in the multivariable model in the groups colostrum management, housing, precalving management and immunity, and feed. Variables were added in order of increasing $P$-value obtained in univariate analysis. The variables age, breed, sex, season, herd size, and region were considered possible confounders and model fit was assessed frequently during model building by adding these covariates as confounders. Biologically relevant interaction terms for colostrum, feeding, and housing management with the variables breed, herd size, sex, and age were tested during model building. The variables for herd size, breed, and region were forced into the final model to adjust for their potential confounding effects. Variables that either had a significant association with the outcome in the univariate analysis or that had a significant association in the multivariable model but were eliminated after adjusting for another variable were tested again in the final multivariable model. Akaike information criterion was used to assess model fit with models producing lower values considered better fit.

\section{Predictors Concerning Demographics}

Age was divided into categories of $<40,40$ to 75 , and $>75$ d. Season was categorized as spring [April-June; reference (R)], summer (July-September), fall (October-December), and winter (January-March) based on distinct climate patterns that may be relevant to BRD, such as precipitation and temperature fluctuations. Milking herd size was categorized as $<250$ (R), 250-999, 1,000-3,999, and >4,000 milking cows. Regions were categorized based on differences in climate and types of dairies as northern California (NCA; R), the northern San Joaquin Valley (NSJV), and greater southern California (GSCA), where the southern San Joaquin Valley and southern California are combined into a single region due to low recruitment success for southern California dairies (Love et al., 2016a; Figure 2).

\section{Predictors Concerning Colostrum Management}

Questions that could be answered with yes or no resulted in dichotomous variables regarding colostrum, 
including supplementation with a colostrum replacer, heat-treatment, bacterial content testing (either amount or type of bacteria before or after heat treatment), storage for greater than $2 \mathrm{~h}$ between milking and feeding calves, and use of a preservative. Colostrum source was categorized as $100 \%$ individual cow or nursing from dam (R), $100 \%$ pooled from multiple cows, or a mix of those sources including colostrum replacer. Colostrum from individual cows and colostrum nursed from the dam were combined into a single category because the quality of the colostrum from these sources was regarded as equal. For those dairies that heat-treated their colostrum, the time between colostrum harvest and heat-treatment was categorized into either less than $(\mathrm{R})$ or more than $6 \mathrm{~h}$. The distribution of storage time for colostrum before feeding in hours underwent a square root transformation to achieve normality. If colostrum was stored for less than $2 \mathrm{~h}$, zero hours were recorded for colostrum storage time. Storage temperature for colostrum was recorded as either room temperature $(\mathrm{R})$, refrigerated, frozen, or first

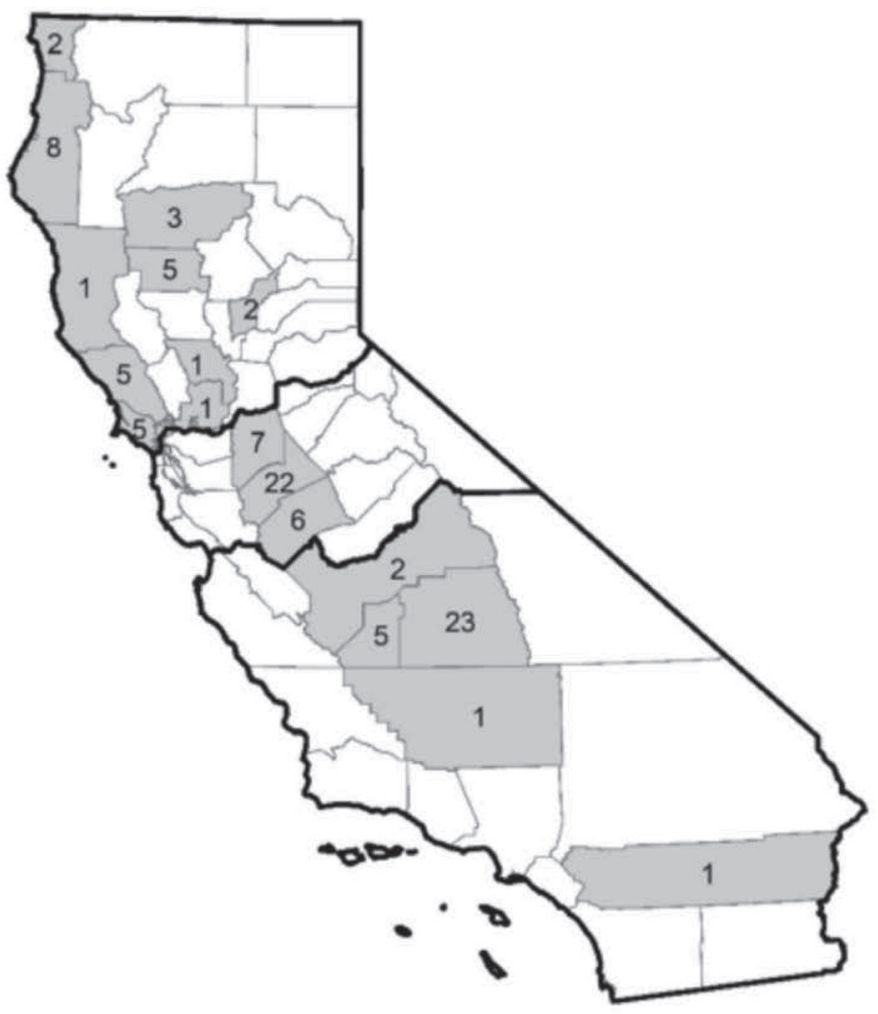

Figure 2. Map of counties in northern California (top section), northern San Joaquin Valley (middle section), and greater southern California (bottom section). Shaded areas contain counties and number of dairies per county sampled for a study of 100 California dairies surveyed between May 2014 and April 2016 relating management practices to bovine respiratory disease prevalence. refrigerated then frozen. A variable for colostrum storage temperature had indicator variables for each of the 4 storage temperatures. The type of storage container for colostrum was dichotomized as solid (R) or bags, as thawing frozen colostrum stored in bags may achieve a more uniform increase in colostrum temperature compared with colostrum stored in plastic bottles and may result in less heat damage to immunoglobulins. The variable for percent of colostrum fed that is from firstcalf heifers was dichotomized into the categories any or no $(\mathrm{R})$ colostrum from first calf heifers. The amount of colostrum fed in the first $12 \mathrm{~h}$ was dichotomized into $<2.84 \mathrm{~L}(\mathrm{R})$ or $\geq 2.84 \mathrm{~L}$ (3 quarts), as feeding $3 \mathrm{~L}$ of colostrum was considered a relevant biological cutpoint (Godden et al., 2009). Four dairies let calves nurse from their dams to meet the calves' colostrum needs; hence, estimates for the amount of colostrum fed in the first $12 \mathrm{~h}$ on these dairies could not be made. In addition, a dichotomous variable for whether or not (R) colostrum was tested for immunoglobulin content and a dichotomous variable for whether or not $(\mathrm{R})$ calves were assessed for failure of transfer of passive immunity based on serum total protein were explored in the model.

\section{Predictors Concerning Housing}

Data to create variables concerning housing of calves were drawn from the questionnaire sections that captured herd-level data as well as from data collected at the individual calf level.

Questionnaire Data. Proportions of calves housed individually or in groups, average group size of grouphoused calves, housing types, weaning age, age when moved from individual hutches to group housing, percent sick preweaned calves moved to a hospital pen, clinical signs to detect $\mathrm{BRD}$, and treatment choices for BRD were used only for descriptive statistics purposes. This was done because these variables provide information about the whole cohort of preweaned calves and are not suitable for analyzing the association of management practices and BRD in individual calves. Data on the percent of calves raised on the premises from other dairies was dichotomized into any or no $(\mathrm{R})$ calves from other dairies on the premises. The variable feeding order by age was created with indicator variables for the answer choices youngest typically fed first (R), calves fed in no particular order, and oldest typically fed first. Only 1 dairy in the sample used a BRD scoring system; hence, the variable describing use of such systems was dropped from analysis. As some dairies gave multiple answers to the question about what surfaces, driven on daily, cover the roads adjacent to the calf-raising area, dichotomized variables for paved, gravel, dirt, or other 
(hay, fly ash, and shavings) surfaces were created and analyzed as separate variables. Similarly, dichotomized variables for dust-abatement procedures were created describing whether or not water, magnesium chloride, or other dust-abatement measures (limiting speed, no driving through the area, restricting entry, oiling of driveway) were implemented (Amato et al., 2014). For the question on how often dust was a problem in the area where preweaned calves were housed, a categorical variable was created with never as the reference and the indicator variables rarely (weeks pass without dust), no week passes by without dust, daily during the nonrainy season, and daily all year round.

Calf-Level Data. The number of calves in the enclosure was dichotomized into group or individual housing type (R). Whether calves had calf-to-calf contact or not $(\mathrm{R})$ was recorded as a dichotomous variable.

Hutch space was defined as the product of the width and depth, as measured during the visit. A categorical variable was created, categorizing the data as less than (R), greater than, or within 1 standard deviation around the mean space for wooden hutches in the sample population, and a separate category for group pens. Hutch elevation from the ground was dichotomized into elevated or not (R). Dichotomous variables for each of the reported floor materials were specified where absence of the specific floor material was the $\mathrm{R}$ [concrete, rubber, sand, Tenderfoot (Tandem Products, Inc., Minneapolis), dirt, grass, wood, and bedding]. In addition, dichotomous variables for slatted floors (wooden floors with slats) and floors that allow airflow (slatted floors and Tenderfoot) were specified. Wall materials were categorized with indicator variables for only wood (R), only metal, only plastic, and a category for a mix of materials or group pens. Fourteen dairies had at least some hutches that were made of a combination of materials, such as wood and metal or metal and plastic. Calves housed in groups were added to the latter category to be able to assess the association of a single hutch material on an individually housed calf without losing group-housed calves or calves in hutches made from a mix of materials in the analysis. In addition, a dichotomous variable for solid walls $(\mathrm{R})$ or nonsolid walls (wire metal or metal bars as material) was specified to explore an association with air flow in hutches and BRD. A categorical variable describing the presence and type of flush system under the calf hutches was specified with 3 levels: no flush (R), fresh water flush, or flush with lagoon water. A categorical variable describing the presence and type of extra shade structures above calf hutches was specified with levels no cover (R), partial roof, complete roof without side walls, complete roof with 1 to 3 side walls, and fully indoors.

\section{Predictors Concerning Precalving Management and Immunity}

The calving space in square meters per cow was calculated by dividing the average number of cows per pen by the dimensions of the maternity pen. Calving space was normalized using the natural log transformation. The percent of calving area that is pasture was dichotomized into any or no calving on pasture (R). The number of times the bedding is changed in the calving pens was dichotomized into less than or equal to 5 times $(\mathrm{R})$ and more than 5 times per month. Typical maternity pen bedding type was summarized into categories of plant fiber (almond shells, rice hulls, straw, wood shavings, sawdust, wood chips, cotton stock, recycled wood product), recycled manure (R), gypsum or lime, dirt (which included sand), and pasture. Those dairies that answered no maternity pen exists or no bedding in maternity pen were assigned to the category sand or dirt. Dichotomous variables were created for the presence or absence $(\mathrm{R})$ of each type of bedding, as multiple dairies used more than 1 type of bedding. The data for the percent of calves removed in $1 \mathrm{~h}$ from the dam was dichotomized into $\geq 95$ and $<95 \%$ (R). Vaccine timing and frequency for cows and calves was dichotomized into whether a type of vaccine was given or not $(\mathrm{R})$. The time since vaccination for each calf was estimated as the time between the reported age when calves receive a certain type of vaccine as stated by the interviewee in the questionnaire and the age of the calf at the time of visit. Dichotomous variables were created describing whether a certain type of vaccine was given at least $7 \mathrm{~d}$ before the visit to account for the fact that there is a variable lag time between vaccine administration and an immune reaction. Hygiene scores for up to 15 cows present in the maternity pen during the dairy visit were transformed into cumulative hygiene scores, which facilitated comparisons of percent of cows scoring 1, 1 and 2, or 1 and 2 and 3 versus the percent of cows scoring the respective remaining scores.

\section{Predictors Concerning Milk Feeding}

Questions that could be answered with yes or no resulted in dichotomous variables including if milk was ever tested for bacterial content (either amount or type of bacteria) both before pasteurization and after pasteurization and if any medication was added to milk or milk replacer $(\mathrm{R}=$ no testing or no medication $)$.

The source of milk for each diet fed on the study dairies was recorded as a percentage of the total diet during the farm visit. For the analysis, these percentages were converted into dichotomous variables per milk source describing whether a calf's diet consisted 
of $>90 \%$ of one of the sources saleable milk, waste or hospital milk, unmedicated milk replacer, or medicated milk replacer for at least $7 \mathrm{~d}$ before the farm visit or not (R). No distinction was made between waste milk from fresh cows and milk from cows in a milk-withdrawal period due to medication. One dairy fed waste from a yogurt producer, which consisted of a water-yogurt mixture created during flushing of the production lines. A separate dichotomous variable for feeding of the yogurt waste product was created. The variable describing whether milk fed had been pasteurized $(\mathrm{R}=$ not pasteurized) contained a category for weaned calves to avoid exclusion of weaned calves from the model. For the number of times calves were fed milk per day, a categorical variable was created with twice feeding as the reference and levels of once daily as well as a level including 3 or 4 times or free choice feeding. Two calves in the study were suckling from the dam based on their age and management of neonatal calves described by the producer and had no amount of milk fed or number of times fed assigned. The total volume of milk fed per day, which was calculated from the number of times calves were fed milk and the volume offered at each feeding, was categorized into $\leq 2.84 \mathrm{~L}$ (3 quarts), between $2.84 \mathrm{~L}$ and up to $5.68 \mathrm{~L}$ (6 quarts; R), and $>5.68$ L. Finally, dichotomous variables for whether or not $(\mathrm{R})$ antimicrobial drugs, vitamins, or electrolytes were added to the milk were explored. The type of medication used to treat BRD was used for descriptive statistics only.

\section{RESULTS}

\section{Descriptive Statistics}

For this cross-sectional study, a convenience sample of 104 grade-A dairies across California was drawn, resulting in an initial study population of 5,034 calves. Of 104 dairies visited during the study period, 4 were eliminated from analysis because calf ages were not available (398 calves, Figure 1). Characteristics of the remaining 100 dairies and calves in the study population included in the analysis are available in Supplemental Table S1 (https://doi.org/10.3168/jds.2018-14773). Mean ( \pm SE) and median reported herd size were 1,717.7 $( \pm 189.9)$ and 1,100 (interquartile range $=535-2,525$ ) milking cows, respectively, with herd size ranging from 110 to 14,000 cows. Average reported breed composition on the study dairies was $71.4 \pm 4.0 \%$ Holsteins, $21.9 \pm$ $3.7 \%$ Jerseys, $0.5 \pm 0.4 \%$ other purebred, and $6.1 \pm$ $1.7 \%$ crossbred (due to rounding, these percentages add up to 99.9). About 1 in 5 dairies $(21.0 \pm 4.1 \%)$ in the study was certified organic, with the majority of organic dairies located in the NCA region $(81.0 \pm 8.8 \%)$.
Calves were reported to be predominantly housed in individual housing units $(91.8 \pm 1.8 \%)$. The most commonly reported type for individually housed calves was the California hutch system (42.0 $\pm 5.0 \%$ of dairies $)-\mathrm{a}$ wooden hutch with 3 separate compartments housing 1 calf each - followed by a type described as hutch with adjacent enclosed individual exercise area $(33.0 \pm 4.7 \%$ of dairies), and other types (31.0 $\pm 4.6 \%$ of dairies). Multiple dairies used more than 1 hutch type $(24 \pm$ $0.43 \%$ of dairies) The mean age in days when calves were moved to group housing $(79.7 \pm 2.2)$ was similar to the mean age in days when weaning occurred $(78.3$ \pm 2.1 . Nasal signs $(72.0 \pm 4.5 \%)$, such as dry nose or nasal discharge, abnormal breathing $(56.0 \pm 5.0 \%)$, droopy ears or head tilt $(44.0 \pm 5.0 \%)$, and cough $(41.0$ $\pm 5.0 \%$ ), were the clinical signs most commonly used to diagnose BRD in calves on study dairies. Most dairies used more than 1 clinical sign to diagnose BRD $(97 \pm 1.7 \%)$. Only 1 of the study dairies used a clinical scoring system for detection of BRD, a hybrid of the Wisconsin and California systems (McGuirk and Peek, 2014; Love et al., 2014). Phenicols (64.4 $\pm 5.6 \%$, which was represented exclusively by florfenicol) and macrolides $(53.4 \pm 5.9 \%)$ were the antibiotic classes most frequently named for the treatment of BRD in calves among the 73 dairies where data on drug choices were available. Of the 73 dairies in the study where drug choices for BRD treatment in calves were known, $86 \pm 4.1 \%$ used more than 1 drug. Almost half the respondents $(49.3 \pm 5.9 \%)$ indicated they were using a nonsteroidal anti-inflammatory drug in the treatment of BRD.

The sample of 4,636 randomly selected calves from the 100 study dairies across California that were either preweaning or days to a few weeks after weaning but still housed individually in hutches consisted of 81.6 $\pm 0.6 \%$ Holstein, $13.1 \pm 0.4 \%$ Jersey, and $5.3 \pm 0.5 \%$ crossbred or other breeds. Of the calves in the study, $73.8 \pm 1.0 \%$ were female and $26.2 \pm 1.0 \%$ were male. Of the 4,324 calves with known exact ages, $52.0 \pm 1.1 \%$ were less than $40 \mathrm{~d}$ old, $38.3 \pm 1.1 \%$ were between 40 and $75 \mathrm{~d}$ old, and $9.6 \pm 0.6 \%$ were 76 to $182 \mathrm{~d}$ old (due to rounding, these percentages add up to 99.9; Supplemental Table S2; https://doi.org/10.3168/jds .2018-14773).

Survey-weighted prevalence estimates for BRD in the sampled calves are shown in Table 1 . Overall prevalence of $\mathrm{BRD}$ was $6.9 \pm 0.7 \%$ with a range of 0 to $37.0 \%$. We found no significant differences in breed-specific prevalence between Holstein $(7.2 \pm 0.8 \%)$, Jersey $(5.7$ $\pm 0.7 \%)$, and other purebred or crossbred calves (5.7 $\pm 2.7 \% ; P=0.49)$. The prevalence in female calves $(6.4 \pm 0.7 \%)$ was numerically smaller than in male calves $(8.4 \pm 1.6 \%)$ but not statistically significant 
Table 1. Prevalence of bovine respiratory disease (BRD) in 4,636 preweaned calves or calves housed in hutches on 100 dairies in California surveyed between May 2014 and April 2016

\begin{tabular}{|c|c|c|c|c|c|}
\hline \multirow[b]{2}{*}{ Item } & \multirow[b]{2}{*}{$\mathrm{N}$} & \multirow{2}{*}{$\begin{array}{l}\text { Prevalence estimate } \\
\%, \text { survey weighted }^{1}\end{array}$} & \multirow[b]{2}{*}{$\mathrm{SE}$} & \multicolumn{2}{|c|}{$95 \% \mathrm{CI}$} \\
\hline & & & & Lower & Upper \\
\hline Overall (range) & 4,636 & $6.9(0-37.0)$ & 0.7 & 5.7 & 8.4 \\
\hline Breed & 4,626 & & & & \\
\hline Holstein & 3,239 & $7.2^{\mathrm{a}}$ & 0.8 & 5.8 & 9.0 \\
\hline Jersey & 1,083 & $5.7^{\mathrm{a}}$ & 0.7 & 4.5 & 7.2 \\
\hline Other & 304 & $5.7^{\mathrm{a}}$ & 2.7 & 2.2 & 13.9 \\
\hline $\operatorname{Sex}^{2}$ & 4,454 & & & & \\
\hline Female & 3,833 & $6.4^{\mathrm{a}}$ & 0.7 & 5.1 & 8.0 \\
\hline Male & 621 & $8.4^{\mathrm{a}}$ & 1.6 & 5.8 & 12.2 \\
\hline $\mathrm{Age}^{3}$ & 4,324 & & & & \\
\hline$<40 \mathrm{~d}$ & 2,117 & $4.5^{\mathrm{a}}$ & 0.8 & 3.2 & 6.3 \\
\hline $40-75 \mathrm{~d}$ & 1,603 & $10.6^{\mathrm{b}}$ & 1.4 & 8.1 & 13.8 \\
\hline$>75 \mathrm{~d}$ & 604 & $6.4^{\mathrm{ab}}$ & 1.8 & 3.7 & 11.1 \\
\hline Management & 4,636 & & & & \\
\hline Conventional & 3,937 & $6.9^{\mathrm{a}}$ & 0.7 & 5.6 & 8.4 \\
\hline Certified organic & 699 & $7.8^{\mathrm{a}}$ & 1.0 & 6.1 & 10.0 \\
\hline Region & 4,636 & & & & \\
\hline Northern California & 1,289 & $9.3^{\mathrm{a}}$ & 0.9 & 7.7 & 11.2 \\
\hline Northern San Joaquin Valley & 1,489 & $4.5^{\mathrm{b}}$ & 0.7 & 3.3 & 6.1 \\
\hline Greater southern California & 1,858 & $7.3^{\mathrm{a}}$ & 0.9 & 5.7 & 9.4 \\
\hline Herd size & 4,636 & & & & \\
\hline$<250$ & 157 & $10.0^{\mathrm{ab}}$ & 2.3 & 6.3 & 15.4 \\
\hline 250-999 & 1,539 & $5.7^{\mathrm{ac}}$ & 0.6 & 4.6 & 7.0 \\
\hline $1,000-3,999$ & 2,487 & $4.4^{\mathrm{c}}$ & 0.5 & 3.5 & 5.4 \\
\hline$\geq 4,000$ & 453 & $10.7^{\mathrm{b}}$ & 1.7 & 7.8 & 14.4 \\
\hline
\end{tabular}

${ }^{a-c}$ Estimates without a superscript in common are different $(P<0.05 /$ number of comparisons $)$ according to Chi-squared analysis adjusted for multiple comparisons with Bonferroni-Dunn adjustment.

${ }^{1}$ Prevalence adjusted for survey sampling within a dairy.

${ }^{2}$ Sex was not recorded for 182 calves.

${ }^{3}$ Only month of birth known for 312 calves.

$(P=0.23)$. The age group between 40 and $75 \mathrm{~d}$ of age had higher prevalence with $10.6 \pm 1.4 \%$ compared with the youngest calves under $40 \mathrm{~d}$ of age, with $4.5 \pm$ $0.8 \%$ affected $(P<0.001)$. In conventionally managed dairies, prevalence $(6.9 \pm 0.7 \%)$ was not different from that in certified organic dairies $(7.8 \pm 1.0 \% ; P=0.45)$. Regionally, the NSJV region had lower prevalence $(4.5$ $\pm 0.7 \%)$ than either NCA $(9.3 \pm 0.9 \%)$ or the GSCA region $(7.3 \pm 0.9 \% ; P=0.007)$.

\section{Multivariable Logistic Regression Model}

Table 2 shows the associations between predictors and the presence of BRD in calves in the study population after testing all main effects, as well as biologically relevant confounders or effect modifiers. The proportion of variance at the dairy level was $57 \pm 8.4 \%$.

Demographics and Seasons. Herd size, breed, and region were forced into the model and were not significantly associated with BRD. Fall compared with spring was significantly associated with BRD [odds ratio (OR) $=7.04,95 \% \mathrm{CI}=1.03-48.16, P=0.047]$.

Predictors Concerning Colostrum Management. None of the predictors describing colostrum management was associated with BRD in our study population. Interactions between heat treatment of colostrum and the source of the colostrum, as well as between the volume of colostrum fed and breed or sex, were explored and none were significant. Additionally, confounding of colostrum related variables by season, herd size, breed, sex, and age was investigated and no change in estimates found after adjusting for possible confounders.

Predictors Concerning Housing. The association of calf-to-calf contact on BRD depended on age, where increased odds of BRD were observed in calves $>75 \mathrm{~d}$ of age that had calf-to-calf contact. $(\mathrm{OR}=9.95,95 \%$ $\mathrm{CI}=1.50-65.86, P=0.02)$ versus those that did not. However, the latter association was not observed in younger calves. When contrasting age groups among those calves with calf-to-calf contact, calves $>75 \mathrm{~d}$ old had almost 3 times higher odds of $\mathrm{BRD}(\mathrm{OR}=2.77$, $95 \% \mathrm{CI}=1.11-6.92, P=0.03)$ than those $<40 \mathrm{~d}$ of age. Calves between 40 and $75 \mathrm{~d}$ old had over 3 times higher odds of BRD compared with calves $<40 \mathrm{~d}$ old $(\mathrm{OR}=$ $3.18,95 \%$ CI $=1.63-6.19, P=0.001$; Table 3$)$. The use of fresh water for flushing under hutches was not associated with BRD; however, the use of a flush lane 
Table 2. Estimated coefficients and odds ratio (OR) estimates from a multivariable generalized linear mixed model with a logit link and random effect for dairy for the association between herd management factors and bovine respiratory disease (BRD) in 4,253 calves on 95 California dairies

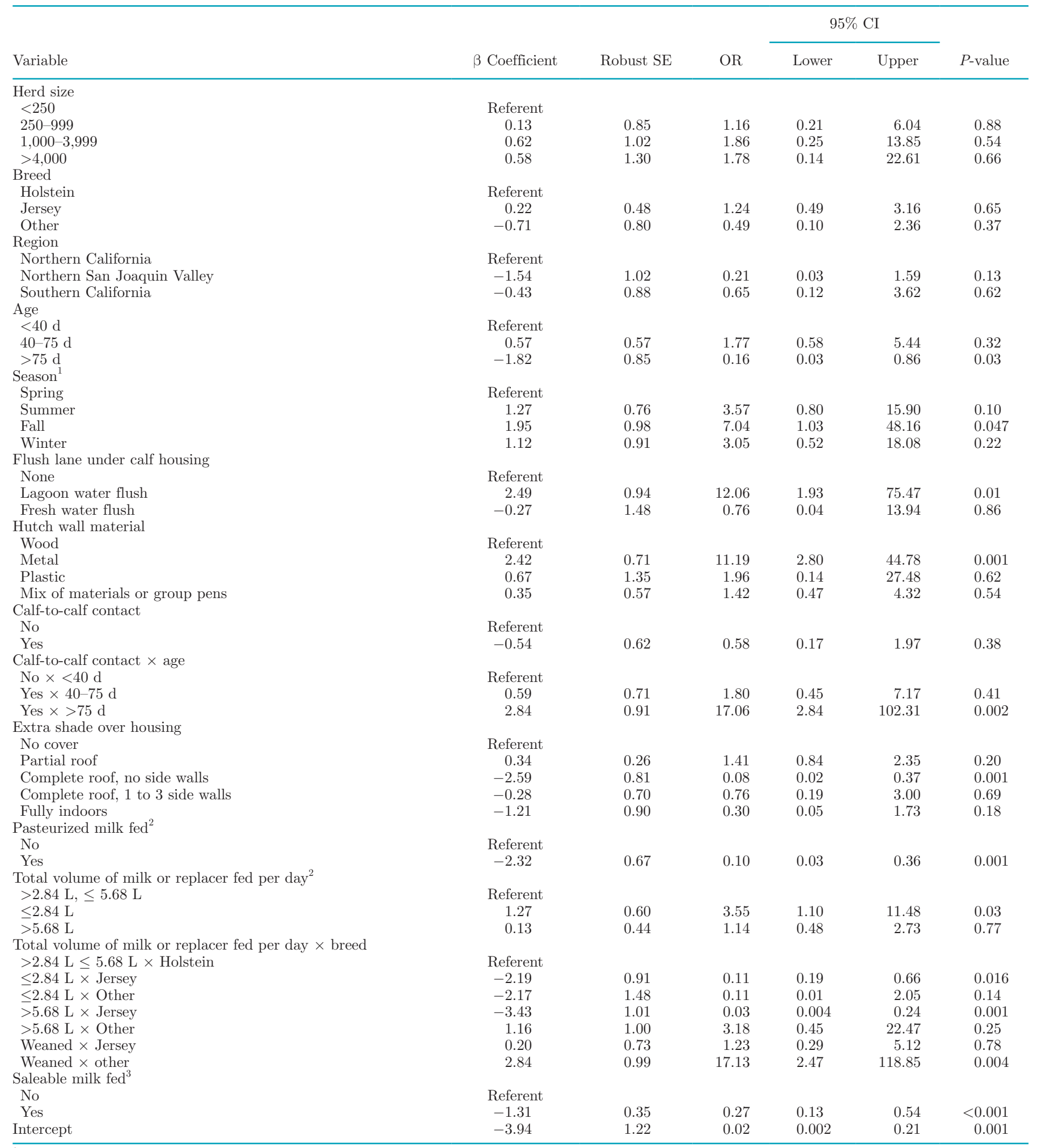

${ }^{1}$ Season: Spring = April-June; summer = July-September; fall = October-December; winter $=$ January-March.

${ }^{2} \mathrm{~A}$ category for weaned calves was omitted because biological interpretation is impossible.

${ }^{3}$ Saleable milk fed: milk diet consists of at least $90 \%$ saleable milk during at least the last $7 \mathrm{~d}$ before the farm visit. 
Table 3. Estimated odds ratios (OR) for joint effects calf-to-calf contact and age on bovine respiratory disease (BRD) in $4,253^{1}$ calves on California dairies

\begin{tabular}{|c|c|c|c|c|c|}
\hline \multirow{2}{*}{$\begin{array}{l}\text { Calf-to-calf contact } \\
\times \text { age interaction }\end{array}$} & \multirow[b]{2}{*}{ OR } & \multirow[b]{2}{*}{$\mathrm{SE}$} & \multicolumn{2}{|c|}{$95 \% \mathrm{CI}$} & \multirow[b]{2}{*}{$P$-value } \\
\hline & & & Lower & Upper & \\
\hline No contact $\times<40 \mathrm{~d}$ & Referent & & & & \\
\hline Contact $\times<40 \mathrm{~d}$ & 0.58 & 0.36 & 0.17 & 1.97 & 0.38 \\
\hline No contact $\times 40-75 \mathrm{~d}$ & Referent & & & & \\
\hline Contact $\times 40-75 \mathrm{~d}$ & 1.05 & 0.85 & 0.21 & 5.11 & 0.96 \\
\hline No contact $x>75 \mathrm{~d}$ & Referent & & & & \\
\hline Contact $\times>75 \mathrm{~d}$ & 9.95 & 9.59 & 1.50 & 65.86 & 0.02 \\
\hline Contact $x<40 \mathrm{~d}$ & Referent & & & & \\
\hline Contact $\times 40-75 \mathrm{~d}$ & 3.18 & 1.08 & 1.63 & 6.19 & 0.001 \\
\hline Contact $\times<40 \mathrm{~d}$ & Referent & & & & \\
\hline Contact $\times>75 \mathrm{~d}$ & 2.77 & 1.29 & 1.11 & 6.92 & 0.03 \\
\hline Contact $\times 40-75 \mathrm{~d}$ & Referent & & & & \\
\hline Contact $\times>75 \mathrm{~d}$ & 0.87 & 0.35 & 0.40 & 1.91 & 0.73 \\
\hline
\end{tabular}

${ }^{1} 383$ of 4,636 calves are not included in the final model due to missing or incomplete data.

under calf hutches using lagoon water versus no use of a flush was positively associated with $\mathrm{BRD}(\mathrm{OR}=12.06$, $95 \% \mathrm{CI}=1.93-75.47, P=0.01)$. Although controlling for other wall materials, calves housed in metal hutches had higher odds of BRD versus those in wood hutches $(\mathrm{OR}=11.19,95 \% \mathrm{CI}=2.80-44.76, P=0.001)$. The 636 metal hutches included 439 hutches with metal roofs and 197 hutches without roofs but located under a separate structure, such as a barn. The wall materials consisted of wire only for 82 hutches, bars only for 66 hutches, bars and wire for 38 hutches, and sheet metal with or without some other metal component for 450 hutches. The presence of an extra shade cover over the hutches in the form of a full roof with no sidewalls was negatively associated with $\mathrm{BRD}(\mathrm{OR}=0.08,95 \% \mathrm{CI}$ $=0.02-0.37, P=0.001)$. Hutch space was not significantly associated with BRD.

Predictors Concerning Precalving Management or Immunity. None of the variables characterizing whether calves or dams had been vaccinated with either a killed, modified live, or intranasal vaccine for the prevention of respiratory disease showed a significant association with BRD. Likewise, none of the other variables in this group was significantly associated with BRD in our study population.

Predictors Concerning Milk Feeding. Feeding pasteurized milk was negatively associated with BRD compared with calves drinking unpasteurized milk (OR $=0.10,95 \% \mathrm{CI}=0.02-0.36, P=0.001)$. We compared calves that had been consuming at least $90 \%$ saleable milk for at least $7 \mathrm{~d}$ before the farm visit, according to milk diets described in the survey, with those that had been on a different diet (i.e., waste milk, milk replacer, or less than $90 \%$ saleable milk in combination with waste milk or milk replacer) and found saleable milk feeding was negatively associated with BRD (OR
$=0.27,95 \% \mathrm{CI}=0.13-0.54, P<0.001)$. We found a significant interaction between the total volume of milk or replacer fed per day and the breed of the calf. Holstein calves compared with Jersey calves fed $<2.84$ $\mathrm{L}$ of milk or replacer had higher odds of BRD (OR = 7.16, 95\% CI $=1.23-41.68, P=0.03)$. Feeding Holstein calves between 2.84 and up to $5.68 \mathrm{~L}$ of milk or replacer compared with $<2.84 \mathrm{~L}$ resulted in lower odds or BRD $(\mathrm{OR}=0.28,95 \% \mathrm{CI}=0.09-0.91, P=0.03)$. Feeding Jersey calves $>5.68 \mathrm{~L}$ was associated with lower odds of BRD compared with feeding between 2.84 and 5.68 $\mathrm{L}(\mathrm{OR}=0.04 .95 \% \mathrm{CI}=0.01-0.26, P=0.001)$ or $<2.84 \mathrm{~L}(\mathrm{OR}=0.09,95 \% \mathrm{CI}=0.01-0.75, P=0.03)$. In addition, feeding Jersey calves $>5.68 \mathrm{~L}$ compared with feeding Holstein calves $>5.68 \mathrm{~L}$ was also associated with lower odds of $\mathrm{BRD}(\mathrm{OR}=0.04,95 \% \mathrm{CI}=$ $0.01-0.28, P=0.001$; Table 4$)$.

Calves Omitted from Analysis. There was no difference between calves in the final model $(\mathrm{n}=4,253)$ and those eliminated from analysis $(\mathrm{n}=781)$ in terms of prevalence of $\operatorname{BRD}(P=0.29)$.

\section{DISCUSSION}

The current study is the first to evaluate BRD in preweaned calves housed on dairies throughout California and to associate BRD in these calves with management practices. Our results suggest that management relative to both housing and calf feeding practices may be the most important areas associated with the prevalence of BRD in young dairy calves on California dairies. Using lagoon water for flushing under hutches, the use of metal hutches, as well as calf-to-calf contact in older calves, and feeding Holstein calves $\leq 2.84 \mathrm{~L}$ of milk or replacer per day were all positively associated with BRD. Pasteurizing milk, feeding saleable milk, feeding 
Jersey calves more than $5.68 \mathrm{~L}$ of milk or replacer per day, and providing extra shelter were all negatively associated with BRD. Interestingly, no associations were found between vaccinating dams or calves or the amount or quality of colostrum fed and BRD.

Management factors significantly associated with BRD in our study may reflect some of the areas where the California dairy industry is less uniform and where changes may have the biggest effect on BRD prevalence. Current knowledge based on numerous studies underscore colostrum management and vaccinations as important components of BRD prevention; however, the current study's dairies may have exhibited uniform colostrum and vaccination practices. The principal component analysis of a California survey on management practices related to bovine respiratory disease in preweaned dairy calves performed in 2013 identified calf housing as the component construct with the largest variation proportion (Love et al., 2016a). The component construct contained the variables hutch style, calf contact, flush used, and waste milk fed to heifers. Three of these variables (hutch style, calf-to-calf contact, and flush) were significantly associated with BRD in our study, supporting the idea that these are areas of highly variable management on California dairies. Although we did not observe an association between the fourth variable in the construct (waste milk fed to heifers) and BRD in our study, we did observe a negative association between BRD and feeding saleable milk for at least $7 \mathrm{~d}$, which is one of the alternatives to feeding waste milk.

\section{External Validity: Comparison of Study Population to Published Averages}

The state-average dairy herd size in California in 2015 was 1,215 milking cows (California Department of Food and Agriculture, 2015), which is less than the average herd size of 1,718 milking cows but close to the median herd size of 1,100 milking cows in our study. Herd sizes are expected to increase (USDA, 2016a), so the calves enrolled in our study likely represent a growing proportion of dairy calves raised in California. Nationally, Holsteins make up $86.0 \%( \pm 1.4 \mathrm{SE})$, Jerseys $7.8 \%( \pm 1.2 \mathrm{SE})$, and other breeds $6.2 \%$ of US dairy cows (USDA, 2016a), compared with $81.6 \%$ Holsteins, $( \pm 0.6 \mathrm{SE}), 13.1 \%$ Jerseys $( \pm 0.4 \mathrm{SE})$, and $5.3 \%$ crossbred $( \pm 0.5 \mathrm{SE})$ calves in our study. Jersey cows have increased in popularity over the last years in California due to their higher milk fat content and potential for higher feed-to-milk conversion ratios among other health related reasons (Mackle et al., 1996; Washburn et al., 2002; White et al., 2002). Although no official statistics for California dairy breeds are available, it may not be unreasonable to assume that Jersey cows are more common in California than nationally. Organic farms make up $6.5 \%$ of California dairies and are overrepresented in our sample (21.0\%; USDA, 2016b); however, this overrepresentation has the advantage of providing more accurate estimates for management practices from this sector of California's dairy industry. The mean percentage $(91.8 \%)$ of calves housed individually on dairies in our study of California dairies

Table 4. Estimated odds ratios (OR) for joint effects for total volume of milk or milk replacer fed per day and breed on bovine respiratory disease (BRD) in $4,253^{1}$ calves on California dairies

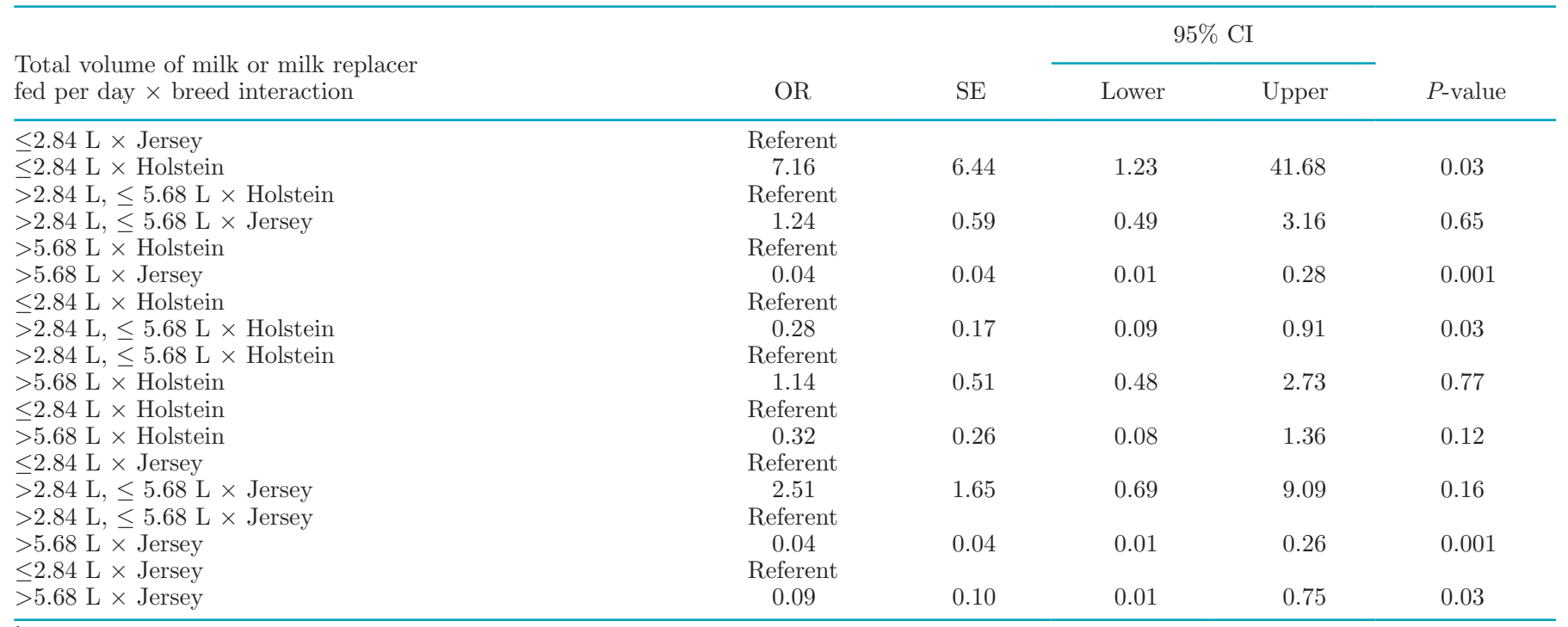

${ }^{1} 383$ of 4,636 calves are not included in the final model due to missing or incomplete data. 
was similar to the proportion of dairies that reported housing calves individually $(93.3 \%)$ in the survey of California dairies by Love et al. (2016a), but larger than the mean nationally (69.7\%; USDA, 2016a). Given the similar order of magnitude in breed distribution and other factors, such as organic status and individual calf housing, results of our study could be extrapolated to dairies in California and elsewhere that fall within the study herds' description and climate.

\section{Prevalence}

Case definitions for BRD vary widely between studies and, therefore, any comparisons of results should be interpreted with caution. Some studies rely on treatment records by dairy staff, whereas others use certain clinical signs for diagnosis, which may also differ between studies. Most epidemiological studies on BRD in dairy calves report incidence rates rather than prevalence. Lago et al. (2006) found a prevalence of $14.3 \%$ in 225 dairy calves housed in barns in the winter in Wisconsin and diagnosed with the Wisconsin BRD scoring system for preweaned calves. Buczinski et al. (2017) found a median prevalence of $8 \%$ in the summer and $15 \%$ in the winter for lung consolidation diagnosed by ultrasound, consistent with BRD in preweaned calves in 39 dairy herds in Québec. Indoor housing and poor ventilation are associated with $\mathrm{BRD}$, so the higher prevalence in the Wisconsin and Québec studies in the winter is not unexpected (Callan and Garry, 2002; Gorden and Plummer, 2010). Both Buczinski et al. (2017) and Lago et al. (2006) reported a gradual increase in prevalence from birth to the sixth and seventh week of life, respectively; we observed a similar rise in prevalence, which continued until $65 \mathrm{~d}$ of age (Supplemental Figure S1; https://doi.org/10.3168/jds.2018-14773). The fact that most of the calves in the current study were housed outdoors may explain the lower prevalence observed of $6.9 \%$, comparable to what Buczinski et al. (2017) observed in the summer. Distributions of the percent of cases by age stratified by breed or region are shown in Supplemental Figures S2 and S3 (https://doi.org/10 $.3168 /$ jds.2018-14773), respectively.

\section{Demographics}

Even though we observed lower prevalence in the NSJV region compared with the other regions of the state, region was not significantly associated with BRD when adjusting for other factors in the multivariable model. We observed lower prevalence in herds between 1,000 and 3,999 milking cows compared with herds with fewer than 250 or more than 4,000 milking cows. Likewise, we found no association between herd size and BRD in the final model. Little evidence exists in the literature to support associations of breed or herd size with BRD.

A previous study found a higher risk of preweaning calf pneumonia in Ottawa for increasing number of calvings per farm per year (Waltner-Toews, 1986). No interpretation for this result was offered by the authors and it may not be relevant to the large California dairy farms of today.

\section{Housing}

In the current study, we observed positive associations of calves housed in hutches made from metal components and BRD. In a study (Karle et al., 2019) based on the same data set, the prevalence of BRD observed in calves housed in wooden hutches $(6.72 \pm$ $0.89 \%$ ) was similar to the prevalence of calves housed in metal hutches $(5.74 \pm 1.16 \%)$. However, in NCA, BRD prevalence for calves housed in hutches or pens made of metal (including wire, pipe, or sheet metal; $15.34 \pm 3.29 \%$ ) was significantly higher compared with those housed in wooden hutches $(3.24 \pm 1.25 \%, P<$ 0.001; Karle et al., 2019). Furthermore, a longitudinal study of 11,300 preweaned calves in California showed that calves housed in hutches made of a combination of wood and metal were at higher risk of BRD compared with calves housed in hutches made of wood only ( $\mathrm{Du}-$ brovsky et al., 2019).

Calf-to-calf contact in the age group over $75 \mathrm{~d}$ was also significantly associated with BRD. Results of past studies on the effects of hutch type on calf health were mainly focused on the effect of plastic type hutches or available space.

Calvo-Lorenzo et al. (2016) housed calves in wooden hutches of 3 sizes between April and July in California to assess the effect of hutch space on health, performance, and respiratory immunity. Calves were raised in conventional California-style wooden hutches and allowed either $1.23,1.85$, or $3.71 \mathrm{~m}^{2} /$ head of space. Those authors concluded that increased space may improve pulmonary immunity and health, although it was not apparent which component of the increased space allowance environment influenced the finding. We did not observe an association of hutch space with BRD in the present study, possibly because hutch material may be the more important component associated with BRD.

The temperature in plastic hutches can average 5 to $10^{\circ} \mathrm{C}$ higher than in wooden hutches and ventilation is comparatively poor, leading to accumulation of heat, carbon dioxide, and humidity (Lamb, 1987; Lammers et al., 1996). Several studies have compared the effect of plastic hutch types on performance and health outcomes in dairy calves, and although agreement exists 
that plastic hutches increase heat stress, none have found significant associations with adverse health outcomes (Macaulay et al., 1995; Higginbotham and Stull, 1997; Peña et al., 2016).

No references regarding the effect of metal style hutches were found in the literature, but heat stress and possibly cold stress are likely associated with metal hutches and may explain the current study findings. Specifically, $69 \%$ of metal hutches housing individual calves on 9 dairies in the current study also had metal roofs, whereas $31 \%$ on 13 dairies had no roof but were under a shed or other shade structure. The difference in health outcomes between hutch types should be researched further, ideally using an experimental study design comparing a limited number of hutch designs, including hutches made from metal components. The large number of different hutch designs in our study made it difficult to elucidate the association between hutch material and BRD and has resulted in large confidence intervals around estimates.

The current study identified a positive association between calf-to-calf contact and BRD in calves older than 75 d. Callan and Garry (2002) recommend spacing hutches at least $1.2 \mathrm{~m}$ (4 feet) apart to prevent calf-to-calf contact and transmission of respiratory pathogens. A distance of $1.2 \mathrm{~m}$ between hutches was rarely, if at all, the case on the California dairies visited for our study, and the feasibility of this strategy and its cost in terms of land needed to raise the same number of calves may be a challenging constraint. In calves that are close to weaning age (in this study those $>75 \mathrm{~d}$ of age), housing- or nutrition-related factors may be less important; thus, calf-to-calf contact with animals shedding pathogens may become a more important factor for their BRD status.

Lagoon flush water could be a source of noxious gases (ammonia, hydrogen sulfide, and methane) that may irritate respiratory mucous membranes, making calves susceptible for opportunistic infections with commensals. The role of lagoon water on a dairy as a source of infective agents has mainly been studied with respect to enteric pathogens, including Mycobacterium avium ssp. paratuberculosis, Salmonella spp. and Escherichia coli and its effect on antimicrobial resistance in some of the pathogens (Aly and Thurmond, 2005; Grewal et al., 2006; Li et al., 2014; Ravva and Sarreal, 2014). Alhamlan et al. (2013) found members of the Flaviviridae in lagoon water samples, a family of viruses that contains bovine viral diarrhea virus (BVDV). Although the viruses were not categorized to the species level in Alhamlan et al. (2013), it is conceivable that lagoon water could be a potential source for exposure to respiratory pathogens if used as flush water, especially if aerosolized particles are created, potentially resulting in in- halation of pathogens. If flush water is close enough to hutch floors, calves could also be able to ingest or have direct exposure of oral or nasal mucosae to pathogens. In addition to BVDV, bovine coronavirus is shed via feces (Oma et al., 2016) and could cause respiratory disease in calves. The significance of lagoon water as a source of pathogenicity with respect to BRD should be further evaluated.

We also observed a negative association between the presence of an additional shade structure over the hutch area and BRD. Shade could reduce heat stress as well as protect from rain or frost, resulting in lower odds of BRD. The association between shade and BRD was not observed for shade structures with 1 to 4 sidewalls, which could be due to an offset of the benefits due to a lack of ventilation. Coleman et al. (1996) studied the effect of supplemental shade structures over polyethylene calf hutches in Alabama during the summer on feed consumption, growth, calf stress, and bedding contamination. Their study found no differences between groups in terms of health-related outcomes, but humidity and coliform counts in bedding were higher in shaded hutches, which may be due to the difference in climate between the 2 states, specifically the higher humidity in Alabama during the summer months.

\section{Season}

The current study findings included higher prevalence in the fall compared with spring. In a comprehensive review on the effects of temperature and humidity on animal diseases, Dennis (1986) concluded that sudden changes of weather might be more important than steady extremes of temperature and humidity to which an animal may adapt. Callan and Garry (2002) also mentioned rapidly changing environmental temperatures as a predisposing factor for BRD.

\section{Feed}

Feeding pasteurized milk versus nonpasteurized milk, including milk replacer, was associated with reduced BRD prevalence. Numerous studies have underlined the importance of pasteurizing milk fed to dairy calves for the prevention of enteric disease as well as exposure to potential respiratory pathogens (e.g., Mycoplasma spp. or BVDV; Pfützner and Sachse, 1996; Callan and Garry, 2002). Mycoplasma spp. are mastitis pathogens that can be shed by clinically or subclinically infected cows and can colonize the nasopharynx of calves fed the milk resulting in otitis and respiratory disease (Pfützner and Sachse, 1996; Walz et al., 1997). Mycoplasma and other bacterial pathogens ingested in the milk can also spread hematogenously to the lungs, where they cause 
respiratory disease (Callan and Garry, 2002). A study from Spain found decreased morbidity and mortality in calves with adequate transfer of passive immunity $(\geq 5.8 \mathrm{~g} / \mathrm{dL}$ serum total protein) during the first $3 \mathrm{wk}$ of life that were fed heat-treated colostrum and pasteurized milk versus those that received nonheat-treated colostrum and nonpasteurized milk (Armengol and Fraile, 2016). A separate study by Godden et al. (2005) found a higher risk of pneumonia in calves fed milk replacer than for calves fed pasteurized waste milk. Those authors argued that the improved immune function was attributable to higher energy and protein intake or the presence of medium-chain fatty acids in the whole milk, which have shown antimicrobial effects in pigs. We also observed a negative association of feeding a diet consisting of at least $90 \%$ saleable milk for at least $7 \mathrm{~d}$ at time of farm visit with BRD versus any other milk diet, including waste milk or milk replacer. Several studies have evaluated the effect of milk intake volume on calf performance (Jasper and Weary, 2002; Johnson et al., 2017). Studies evaluating the amounts of milk fed to calves on health outcomes have found mixed effects.

Medrano-Galarza et al. (2018) found no associations between within-pen prevalence of BRD and peak milk allowance in a study of majority Holstein group-housed dairy calves fed with automated milk feeders. However, calves in that study were fed at least $4 \mathrm{~L}$ per calf per day before and at least $6 \mathrm{~L}$ per calf per day after introduction to the group pen. A different study, similarly found no difference in incidence of BRD between Holstein calves fed a maximum of 6 or $8 \mathrm{~L}$ of milk replacer per day in a randomized trial comparing performance and health response of dairy calves offered different milk replacer allowances (Bach et al., 2013). Higher amount and quality of milk replacer fed was found to be associated with superior immune function in Jersey calves (Ballou, 2012). The group of Holstein calves fed $\leq 2.84 \mathrm{~L}$ of milk or replacer per day in our study was fed less than the lowest amounts supplied to calves in the above-mentioned studies and were likely not able to consume enough starter to meet their nutrient requirements for growth and development if they were under 2 mo old (Jasper and Weary, 2002). Results in our study showed increased odds of BRD for Holstein calves fed $\leq 2.84 \mathrm{~L}$ and decreased odds of BRD in Jersey calves fed $>5.68 \mathrm{~L}$ of milk or replacer, which may reflect the effects of nutrition on immune function but should be interpreted with caution due to the relatively small samples in those categories, resulting in large confidence intervals for estimates. Restricting the analysis to calves $\leq 75 \mathrm{~d}$ of age did not change the sign or statistical significance of contrasts except for the comparison of $>5.68$ to $\leq 2.84 \mathrm{~L}$ of milk or replacer in Jersey calves, which became nonsignificant $(P=0.22)$.
Future research should quantify the benefits of saleable milk compared with waste milk or milk replacer further, as well as how the association with BRD is modified by pasteurization and amount of milk fed in the major dairy breeds.

\section{Maternity and Immunity}

The current study found no significant associations between calf or dam vaccination status for respiratory pathogens and BRD in the study population. Due to the cross-sectional nature, it was not possible to ascertain the vaccination status of calves in the study with certainty, instead we relied on the in-person surveyreported vaccination protocols, although respondents were asked to answer the questions with respect to the current cohort of calves on their premises during the visit. If calves were older than the age of vaccination stated in the questionnaire they were considered vaccinated. However, the true vaccination status and time since vaccination may have been different for an unknown number of calves. No associations between reported vaccination status and BRD were found when calves at least $7 \mathrm{~d}$ older than age of vaccination were considered vaccinated to account for time to initiate an immune response. Our findings correlated with a randomized clinical trial by Windeyer et al. (2012) of 2,874 heifer calves on 19 commercials dairy farms in Minnesota and Ontario, in which they found no difference in risk of BRD between calves vaccinated at 2 or 5 wk of age or both with a commercial multivalent modified live vaccine against the common respiratory viruses compared with a placebo control group. Those authors cited interference by maternal antibodies, unresponsiveness of the neonatal immune system, timing of immunity relative to pathogen exposure, disease caused by pathogens other than the viruses in the vaccine, or herd immunity as possible explanations for their findings. The vaccination of dams may only be effective in preventing calfhood BRD in combination with adequate transfer of passive immunity. Many factors can affect the efficiency of transfer of passive immunity, from the amount, quality, and timing of colostrum fed to the storage time and temperature (Pithua et al., 2013, Williams et al., 2014, Lago et al., 2018). It is possible that any positive effect of dam vaccination may have been diluted by other variables affecting transfer of passive immunity. In a longitudinal study following over 11,300 preweaned calves on 5 dairies in California and associating management factors to BRD in the calves, vaccinating dams with either a killed or a modified live vaccine reduced the risk of disease in calves. (Dubrovsky et al., 2019). The longitudinal study design combined with close follow-up of management practices 
by verifying changes every 1 to 4 mo in a few dairies may have been the reason that study found these associations, whereas in the present study they were not apparent. The complexity of factors involving vaccination of neonatal calves combined with the present study design make it difficult to extend recommendations based on our findings.

\section{Colostrum Management}

Although the benefits of colostrum on calf health have been previously reported (DeNise et al., 1989; Weaver et al., 2000), we found no association between volume, source, quality, or storage conditions of colostrum and BRD in the study herds. Windeyer et al. (2014) reported serum total protein levels $\geq 5.7 \mathrm{~g} / \mathrm{dL}$ during the first week of life as well as supplementation with an antibody product at birth to be negatively associated with BRD, but the predictive value positive was low (18\%) when using serum total protein levels at the cutpoint of $<5.7 \mathrm{~g} / \mathrm{dL}$ to predict BRD. In a study by Virtala et al. (1999), low postcolostral total serum IgG concentrations $\leq 1,200 \mathrm{mg} / \mathrm{dL}$ was associated with increased risk of $\mathrm{BRD}$ in a prospective cohort study of 410 preweaned heifer calves. Diagnostic accuracy of prediction in that study was $54 \%$. Both groups of authors (Windeyer et al., 2014; Virtala et al., 1999) stated that additional factors could play a role in the development of BRD. The current study did not include data on failure of transfer of passive immunity for the study calves. The data on volume of colostrum fed as well as whether colostrum from first-calf heifers was used and if the quality of colostrum was assessed served as proxies for adequate passive transfer. The fact that all colostrum-management variables had to be assessed on a herd-level basis may have masked the effect of colostrum quality fed to individual calves in the study, as it was unknown which calves received colostrum from first-calf heifers or colostrum stored at a certain temperature or for a certain amount of time if there was variability within a dairy.

\section{Limitations}

The cross-sectional nature of the study prohibits drawing of causal inferences. Although a longitudinal study design would have allowed us to draw causal inferences, the large number and wide geographic distribution of dairies enrolled did not allow such a study. However, findings reported here provide the basis for hypothesizing potentially causal factors and promote the design of further studies with longitudinal design to directly examine housing and management factors found to be associated with BRD. Participating dairies were not chosen randomly from all dairies in California, and it could be argued that those willing to invite researchers onto their dairy might differ from those who do not. However, considering the wide geographic distribution of dairies, the inclusion of both organic and conventional operations, and a wide range of herd sizes, as well as representation of Holstein and Jersey breeds, in the sample further ensures that the spectrum of California dairy operations was captured in the current study population.

\section{CONCLUSIONS}

The California dairy industry contains both very large herds with several thousand cows in the central and southern parts of the state, as well as many organic dairies in the northern part of the state, and hence may collectively represent a large number of US dairies despite the state's unique dairy industry. The current study evaluated which management practices on California dairies were associated with the prevalence of BRD in preweaned calves. Housing-related factors positively associated with BRD included using recycled flush water, housing calves in metal hutches, and calfto-calf contact in calves over $75 \mathrm{~d}$ of age. Feeding Holstein calves less $\leq 2.84 \mathrm{~L}$ of milk or replacer per day was also positively associate with BRD. Negatively associated with BRD were an additional shade structure over hutches, feeding pasteurized milk and feeding saleable milk, as well as feeding more than $5.68 \mathrm{~L}$ of milk or replacer to Jersey calves. The fact that no associations between colostrum management and vaccinationrelated factors were found in the current study may indicate the lack of variability regarding these factors in the California dairy industry, rather than diminished importance in prevention of BRD.

\section{ACKNOWLEDGMENTS}

The authors thank the dairy owners, their staff, and herd veterinarians for their participation and Jeffery Stackhouse (Cooperative Extension, Division of Agriculture and Natural Resources, University of California, Eureka), Nyles Peterson (Cooperative Extension, Division of Agriculture and Natural Resources, University of California, San Bernardino), and Paul Rossito, Courtney Faria, and Arianna Villarreal (Veterinary Medicine Teaching and Research Center, School of Veterinary Medicine, University of California-Davis, Tulare) for technical assistance. Funding for this project was provided by the University of California's Division of Agriculture and Natural Resources, Competitive Grants 
Program (PI: S. Aly, Project 1753), USDA National Institute of Food and Agriculture, Washington, DC (PI: S. Aly; Projects: CA-V-PHR-4041-H and CALVAH-360), and the Dairy Epidemiology Lab (Aly Lab), School of Veterinary Medicine, University of California, Davis.

\section{REFERENCES}

Alhamlan, F. S., M. M. Ederer, C. J. Brown, E. R. Coats, and R. L. Crawford. 2013. Metagenomics-based analysis of viral communities in dairy lagoon wastewater. J. Microbiol. Methods 92:183-188. https://doi.org/10.1016/j.mimet.2012.11.016.

Aly, S. S., and M. C. Thurmond. 2005. Evaluation of Mycobacterium avium subsp paratuberculosis infection of dairy cows attributable to infection status of the dam. J. Am. Vet. Med. Assoc. 227:450-454.

Amato, F., A. Karanasiou, P. Cordoba, A. Alastuey, T. Moreno, F. Lucarelli, S. Nava, G. Calzolai, and X. Querol. 2014. Effects of road dust suppressants on PM levels in a Mediterranean urban area. Environ. Sci. Technol. 48:8069-8077. https://doi.org/10 $.1021 / \mathrm{es502496s.}$

Armengol, R., and L. Fraile. 2016. Colostrum and milk pasteurization improve health status and decrease mortality in neonatal calves receiving appropriate colostrum ingestion. J. Dairy Sci. 99:4718 4725. https://doi.org/10.3168/jds.2015-10728.

Bach, A., M. Terre, and A. Pinto. 2013. Performance and health responses of dairy calves offered different milk replacer allowances. J. Dairy Sci. 96:7790-7797. https://doi.org/10.3168/jds.2013-6909.

Ballou, M. A. 2012. Immune responses of Holstein and Jersey calves during the preweaning and immediate postweaned periods when fed varying planes of milk replacer. J. Dairy Sci. 95:7319-7330. https://doi.org/10.3168/jds.2012-5970.

Box, G. E. P., and P. W. Tidwell. 1962. Transformation of the independent variables. Technometrics 4:531-550.

Buczinski, S., M. E. Borris, and J. Dubuc. 2017. Herd-level prevalence of the ultrasonographic lung lesions associated with bovine respiratory disease and related environmental risk factors. J. Dairy Sci. 101:2423-2432. https://doi.org/10.3168/jds.2017-13459.

California Department of Food and Agriculture. 2015. California Dairy Statistics 2015. Pages 1-20 in California Dairy Statistics Annual. Division of Marketing Services, Dairy Marketing Branch, Sacramento, CA.

California Department of Food and Agriculture. 2016. California Dairy Statistics 2016. Pages 1-20 in California Dairy Statistics Annual. Division of Marketing Services, Dairy Marketing Branch, Sacramento, CA.

Callan, R. J., and F. B. Garry. 2002. Biosecurity and bovine respiratory disease. Vet. Clin. North Am. Food Anim. Pract. 18:57-77. https://doi.org/10.1016/S0749-0720(02)00004-X.

Calvo-Lorenzo, M. S., L. E. Hulbert, A. L. Fowler, A. Louie, L. J. Gershwin, K. E. Pinkerton, M. A. Ballou, K. C. Klasing, and F. M. Mitloehner. 2016. Wooden hutch space allowance influences male Holstein calf health, performance, daily lying time, and respiratory immunity. J. Dairy Sci. 99:4678-4692. https://doi.org/10.3168/jds .2016-10888.

Coleman, D. A., B. R. Moss, and T. A. McCaskey. 1996. Supplemental shade for dairy calves reared in commercial calf hutches in a southern climate. J. Dairy Sci. 79:2038-2043.

DeNise, S. K., J. D. Robison, G. H. Stott, and D. V. Armstrong. 1989. Effects of passive immunity on subsequent production in dairy heifers. J. Dairy Sci. 72:552-554. https://doi.org/10.3168/ jds.S0022-0302(89)79140-2.

Dennis, M. J. 1986. The effects of temperature and humidity on some animal diseases-A review. Br. Vet. J. 142:472-485.

Dubrovsky, S. A., A. L. Van Eenennaam, B. M. Karle, P. V. Rossitto, T. W. Lehenbauer, and S. S. Aly. 2019. Epidemiology of bovine respiratory disease (BRD) in preweaned calves on California dairies: The BRD 10K study. J. Dairy Sci. 102:7306-7319. https://doi .org/10.3168/jds.2018-14774.
Farmers Assuring Responsible Management. 2016. Animal Care Reference Manual. N. M. P. Federation, ed. National Milk Producers Federation, Arlington, VA.

Godden, S. M., J. P. Fetrow, J. M. Feirtag, L. R. Green, and S. J. Wells. 2005. Economic analysis of feeding pasteurized nonsaleable milk versus conventional milk replacer to dairy calves. J. Am. Vet. Med. Assoc. 226:1547-1554.

Godden, S. M., D. M. Haines, K. Konkol, and J. Peterson. 2009. Improving passive transfer of immunoglobulins in calves. II: Interaction between feeding method and volume of colostrum fed. J. Dairy Sci. 92:1758-1764. https://doi.org/10.3168/jds.2008-1847.

Gorden, P. J., and P. Plummer. 2010. Control, management, and prevention of bovine respiratory disease in dairy calves and cows. Vet. Clin. North Am. Food Anim. Pract. 26:243-259. https://doi.org/ 10.1016/j.cvfa.2010.03.004.

Grewal, S. K., S. Rajeev, S. Sreevatsan, and F. C. Michel Jr.. 2006. Persistence of Mycobacterium avium ssp. paratuberculosis and other zoonotic pathogens during simulated composting, manure packing, and liquid storage of dairy manure. Appl. Environ. Microbiol. 72:565-574. https://doi.org/10.1128/AEM.72.1.565-574.2006.

Higginbotham, G. E., and C. L. Stull. 1997. Performance and health of dairy calves using different types of commercial housing. Prof. Anim. Sci. 13:18-23.

Jasper, J., and D. M. Weary. 2002. Effects of ad libitum milk intake on dairy calves. J. Dairy Sci. 85:3054-3058. https://doi.org/10.3168/ jds.S0022-0302(02)74391-9.

Johnson, K. F., N. Chancellor, C. C. Burn, and D. C. Wathes. 2017. Analysis of pre-weaning feeding policies and other risk factors influencing growth rates in calves on 11 commercial dairy farms. Animal 12:1413-1423. https://doi.org/10.1017/S1751731117003160.

Karle, B. M., G. U. Maier, W. J. Love, S. A. Dubrovsky, D. R. Williams, R. J. Anderson, A. L. Van Eenennaam, T. W. Lehenbauer, and S. S. Aly. 2019. Regional management practices and prevalence of bovine respiratory disease in California's preweaned dairy calves. J. Dairy Sci. 102:7583-7596. https://doi.org/10.3168/jds 2018-14775.

Lago, A., S. M. McGuirk, T. B. Bennett, N. B. Cook, and K. V. Nordlund. 2006. Calf respiratory disease and pen microenvironments in naturally ventilated calf barns in winter. J. Dairy Sci. 89:40144025. https://doi.org/10.3168/jds.S0022-0302(06)72445-6.

Lago, A., M. Socha, A. Geiger, D. Cook, N. Silva-Del-Rio, C. Blanc, R. Quesnell, and C. Leonardi. 2018. Efficacy of colostrum replacer versus maternal colostrum on immunological status, health, and growth of preweaned dairy calves. J. Dairy Sci. 101:1344-1354. https://doi.org/10.3168/jds.2017-13032.

Lamb, R. C., B. K. Morrow, M. Arambel, and C. W. Arave. 1987. Comparison of plastic domes with wooden hutches for housing of dairy calves. J. Dairy Sci. 70(Suppl. 1):145.

Lammers, B. P., J. W. vanKoot, A. J. Heinrichs, and R. E. Graves 1996. The effect of plywood and polyethylene calf hutches on heat stress. Appl. Eng. Agric. 12:741-745. https://doi.org/10.13031/ 2013.25707.

Li, X., N. Watanabe, C. Xiao, T. Harter, B. McCowan, Y. Liu, and E. R. Atwill. 2014. Antibiotic-resistant E. coli in surface water and groundwater in dairy operations in Northern California. Environ. Monit. Assess. 186:1253-1260.

Love, W. J., T. W. Lehenbauer, B. M. Karle, L. E. Hulbert, R. J. Anderson, A. L. Van Eenennaam, T. B. Farver, and S. S. Aly. 2016a. Survey of management practices related to bovine respiratory disease in preweaned calves on California dairies. J. Dairy Sci 99:1483-1494. https://doi.org/10.3168/jds.2015-9394.

Love, W. J., T. W. Lehenbauer, P. H. Kass, A. L. Van Eenennaam, and S. S. Aly. 2014. Development of a novel clinical scoring system for on-farm diagnosis of bovine respiratory disease in pre-weaned dairy calves. PeerJ 2:e238. https://doi.org/10.7717/peerj.238.

Love, W. J., T. W. Lehenbauer, A. L. Van Eenennaam, C. M. Drake, P. H. Kass, T. B. Farver, and S. S. Aly. 2016b. Sensitivity and specificity of on-farm scoring systems and nasal culture to detect bovine respiratory disease complex in preweaned dairy calves. J. Vet. Diagn. Invest. 28:119-128. https://doi.org/10.1177/ 1040638715626204 
Macaulay, A. S., G. L. Hahn, D. H. Clark, and D. V. Sisson. 1995. Comparison of calf housing types and tympanic temperature rhythms in Holstein calves. J. Dairy Sci. 78:856-862. https://doi .org/10.3168/jds.S0022-0302(95)76698-X.

Mackle, T. R., P. C. Stakelum, G. K. Bryant, A. M. Mac, and K. L. Millan. 1996. Feed conversion efficiency, daily pasture intake, and milk production of primiparous Friesian and Jersey cows calved at two different liveweights. N. Z. J. Agric. Res. 39:357-370.

McGuirk, S. M., and S. F. Peek. 2014. Timely diagnosis of dairy calf respiratory disease using a standardized scoring system. Anim. Health Res. Rev. 15:145-147. https://doi.org/10.1017/ S1466252314000267.

Medrano-Galarza, C., S. J. LeBlanc, A. Jones-Bitton, T. J. DeVries, J. Rushen, A. Marie de Passille, M. I. Endres, and D. B. Haley. 2018. Associations between management practices and within-pen prevalence of calf diarrhea and respiratory disease on dairy farms using automated milk feeders. J. Dairy Sci. 101:2293-2308. https: //doi.org/10.3168/jds.2017-13733.

Moineddin, R., F. I. Matheson, and R. H. Glazier. 2007. A simulation study of sample size for multilevel logistic regression models. BMC Med. Res. Methodol. 7:34. https://doi.org/10.1186/1471-2288-7 -34 .

Oma, V. S., M. Traven, S. Alenius, M. Myrmel, and M. Stockstad. 2016. Bovine coronarvirus in naturally and experimentally exposed calves; viral shedding and the potential for transmission. Virol. J. 13. https://doi.org/10.1186/s12985-016-0555-x.

Panciera, R. J., and A. W. Confer. 2010. Pathogenesis and pathology of bovine pneumonia. Vet. Clin. North Am. Food Anim. Pract. 26:191-214. https://doi.org/10.1016/j.cvfa.2010.04.001.

Peña, G., C. Risco, E. Kunihiro, M. J. Thatcher, and P. J. Pinedo. 2016. Effect of housing type on health and performance of preweaned dairy calves during summer in Florida. J. Dairy Sci. 99:1655-1662. https://doi.org/10.3168/jds.2015-10164.

Pfützner, H., and K. Sachse. 1996. Mycoplasma bovis as an agent of mastitis, pneumonia, arthritis and genital disorders in cattle. Rev. Sci. Tech. 15:1477-1494.

Pithua, P., S. S. Aly, D. M. Haines, J. D. Champagne, J. R. Middleton, and S. E. Poock. 2013. Efficacy of feeding a lacteal-derived colostrum replacer or pooled maternal colostrum with a low IgG concentration for prevention of failure of passive transfer in dairy calves. J. Am. Vet. Med. Assoc. 243:277-282. https://doi.org/10 $.2460 /$ javma.243.2.277.

Ravva, S. V., and C. Z. Sarreal. 2014. Survival of Salmonella enterica in aerated and nonaerated wastewaters from dairy lagoons. Int. J. Environ. Res. Public Health 11:11249-11260. https://doi.org/10 .3390/ijerph111111249.

Scheaffer, R. L., W. Mendenhall, R. L. Ott, and K. G. Gerow. 2012. Survey Sampling. 7th ed. Brooks/Cole, Boston, MA.

USDA. 1994. National Dairy Heifer Project 1991-1992, Dairy Heifer Morbidity, Mortality, and Health Management Focusing on Preweaned Heifers. USDA:APHIS:VS, CEAH. Fort Collins, CO.

USDA. 2010. Dairy 2007, Heifer Calf Health and Management Practices on U.S. Dairy Operations, 2007 USDA:APHIS:VS, CEAH. Fort Collins, CO.
USDA. 2011, Economic Research Service. Organic Production. Accessed Dec. 2, 2017. https://www.ers.usda.gov/data-products/ organic-production/organic-production.

USDA. 2012. Dairy Heifer Raiser, 2011 USDA-APHIS-VS, CEAH, National Animal Health Monitoring System (NAHMS), Fort Collins, CO.

USDA. 2016a. Dairy 2014, Dairy Cattle Management Practices in the United States, 2014. USDA:APHIS:VS, CEAH. Fort Collins, CO.

USDA. 2016b. Certified Organic Survey, 2015 Summary, September 2016. National Agricultural Statistics Service, Washington, DC.

Virtala, A. M., Y. T. Grohn, G. D. Mechor, and H. N. Erb. 1999. The effect of maternally derived immunoglobulin $\mathrm{G}$ on the risk of respiratory disease in heifers during the first 3 months of life. Prev. Vet. Med. 39:25-37.

Waltner-Toews, D. M. S. W. M. A. H. 1986. Dairy calf management, morbidity and mortality in Ontario Holstein herds. III. Association of management with morbidity. Prev. Vet. Med. 4:137-158.

Walz, P. H., T. P. Mullaney, J. A. Render, R. D. Walker, T. Mosser, and J. C. Baker. 1997. Otitis media in preweaned Holstein dairy calves in Michigan due to Mycoplasma bovis. J. Vet. Diagn. Invest. 9:250-254. https://doi.org/10.1177/104063879700900305.

Washburn, S. P., S. L. White, J. T. Green Jr., and G. A. Benson. 2002. Reproduction, mastitis, and body condition of seasonally calved Holstein and Jersey cows in confinement or pasture systems. J. Dairy Sci. 85:105-111. https://doi.org/10.3168/jds.S0022 $-0302(02) 74058-7$.

Weaver, D. M., J. W. Tyler, D. C. VanMetre, D. E. Hostetler, and G. M. Barrington. 2000. Passive transfer of colostral immunoglobulins in calves. J. Vet. Intern. Med. 14:569-577. https://doi.org/10 $.1111 /$ j.1939-1676.2000.tb02278.x.

White, S. L., G. A. Benson, S. P. Washburn, and J. T. Green Jr. 2002. Milk production and economic measures in confinement or pasture systems using seasonally calved Holstein and Jersey cows. J. Dairy Sci. 85:95-104. https://doi.org/10.3168/jds.S0022-0302(02)74057 -5 .

Williams, D. R., P. Pithua, A. Garcia, J. Champagne, D. M. Haines, and S. S. Aly. 2014. Effect of three colostrum diets on passive transfer of immunity and preweaning health in calves on a California dairy following colostrum management training. Vet. Med. Int. 2014:698741. https://doi.org/10.1155/2014/698741.

Windeyer, M. C., K. E. Leslie, S. M. Godden, D. C. Hodgins, K. D. Lissemore, and S. J. LeBlanc. 2012. The effects of viral vaccination of dairy heifer calves on the incidence of respiratory disease, mortality, and growth. J. Dairy Sci. 95:6731-6739. https://doi.org/10 $.3168 /$ jds.2012-5828.

Windeyer, M. C., K. E. Leslie, S. M. Godden, D. C. Hodgins, K. D. Lissemore, and S. J. LeBlanc. 2014. Factors associated with morbidity, mortality, and growth of dairy heifer calves up to 3 months of age. Prev. Vet. Med. 113:231-240. https://doi.org/10.1016/j .prevetmed.2013.10.019. 